\section{RECAI}

ACCN River on Givion
RECAI Revista de Estudios en Contaduría,

Administración e Infomática

ISSN: 2007-5278

mrdemunerf@uaemex.mx

Universidad Autónoma del Estado de México

México

\title{
La COVID-19 y las microempresas de comercio al por menor de la Región II Atlacomulco, Estado de México. Un acercamiento mediante análisis factorial en el primer trimestre de 2021
}

Baltazar Vilchis, Carlos Alberto; Velázquez Ramírez, Juan Manuel

La COVID-19 y las microempresas de comercio al por menor de la Región II Atlacomulco, Estado de México. Un acercamiento mediante análisis factorial en el primer trimestre de 2021

RECAI Revista de Estudios en Contaduría, Administración e Infomática, vol. 11, núm. 30, 2022

Universidad Autónoma del Estado de México, México

Disponible en: https://www.redalyc.org/articulo.oa? $\mathrm{id}=637969396002$ 
Artículos

\title{
La COVID-19 y las microempresas de comercio al por menor de la Región II Atlacomulco, Estado de México. Un acercamiento mediante análisis factorial en el primer trimestre de 2021
}

\author{
Carlos Alberto Baltazar Vilchis cabvman@outlook.com \\ Universidad Internacional Iberoamericana, México \\ Juan Manuel Velázquez Ramírezjuanmv@iteso.mx \\ Instituto Tecnológico y de Estudios Superiores de Occidente, México
}

RECAI Revista de Estudios en Contaduría, Administración e Informática, vol. 11, núm. 30, 2022

Universidad Autónoma del Estado de México, México

Recepción: 23 Agosto 2021

Aprobación: 11 Noviembre 2021

Redalyc: https://www.redalyc.org/ articulo.oa?id=637969396002
Resumen: El presente trabajo de investigación midió el impacto de la pandemia de COVID-19 considerando factores sobre tecnologías de la información, financieros, fiscales y de responsabilidad social en las microempresas del sector comercio al por menor en los municipios de la Región II Atlacomulco, del Estado de México durante el primer trimestre del año 2021. Se elaboró un instrumento denominado FFFRSICOVID19 constituido por 44 ítems (8 socioeconómicas y 36 divididas en 7 factores) que reportan un Alfa de Cronbach de .892, lo cual demostró una fiabilidad aceptable. Además, el análisis factorial exploratorio, como metodología para la evaluación de los datos obtenidos, indicó una correlación significativa entre todas las variables, excepto COVID-19 que se relacionó únicamente con la variable financiamiento. Esto denota el bajo nivel de apoyo por parte de las autoridades hacia este sector, así como la capacidad que han tenido para continuar sus labores económicas a través del uso de las TIC y las diferentes plataformas de comunicación con sus clientes.

Palabras clave: COVID-19, microempresas, comercio al por menor, Atlacomulco, análisis factorial exploratorio, TIC.

Keywords: COVID-19, microenterprises, retail-trade, Atlacomulco, exploratory factor analysis, ICT

\section{Introducción}

La correcta metodología para el análisis de los datos recolectados a través de medios electrónicos es hoy en día una característica con una importancia trasce ndental para cualquier organización con la visión de permanecer a la vanguardia de su sector, es aquí donde la informática provee de herramientas y metodologías para su valuación con la finalidad de brindar soporte a la toma de decisiones de las organizaciones. La actual situación de la pandemia del SARS-CoV-2 (COVID-19) ha venido a transformar el mundo que conocíamos hacía una nueva "normalidad" donde muchas microempresas han venido a cierre debido a las bajas ventas a causa del confinamiento obligado por el Gobierno de México. Algunas han sobrevivido, el conocer cómo lo han logrado es fundamental para lograr concebir el modelo de negocio adoptado con la finalidad de 
replicarlo, en la medida de lo posible, en otras unidades económicas, y mejorar los ratios locales y nacionales.

Se define como microempresa a aquellas organizaciones que producen y distribuyen bienes o servicios en los diferentes mercados, con la finalidad de obtener un lucro económico, destacan por su agilidad y flexibilidad al minimizar los procesos burocráticos y de modificar su estructura a su conveniencia administrativa, dicha situación les permite afrontar las diversas crisis de una forma rápida y efectiva, son cercanas a sus clientes lo cual les permite atender sus necesidades de forma pronta y expedita, todas estas características les provee de una ventaja competitiva pues reconocen incluso nichos de mercado que las grandes empresas aún no explotan, sus relaciones interpersonales se vuelven más estrechas debido a que se encuentran constituidas por no más de diez individuos, lo cual también permite a sus dirigentes identificar y medir el rendimiento de estos en beneficio de la unidad de negocio.

Suponen aproximadamente, el $90 \%$ del sector empresarial en todo el mundo, incluso el porcentaje puede ser un poco más acercándose a un posible 95\% (Filión, 2011, p.11), contribuyendo en gran medida al producto interno bruto (PIB), en México simbolizan el 97.6\% del sector, concentrando el $75.4 \%$. Su papel es importante en países en vías de desarrollo en cuanto a la creación de empleo y el crecimiento económico de sus regiones, coadyuvan hasta con un $45 \%$ al empleo formal y en un $33 \%$ en cuanto al PIB en economías emergentes, brindan trabajo a estratos vulnerables como mujeres y jóvenes. (Durán, 2017)

Con base en lo anterior, la principal razón de la presente investigación radicó en la importancia y conveniencia de medir el impacto de la pandemia de COVID-19 e identificar cómo los factores sobre tecnologías de la información, financieros, fiscales y de responsabilidad social trajeron repercusiones en las microempresas del sector comercio al por menor de la región II Atlacomulco, constituida por los siguientes ayuntamientos (Copladem, 2017):

- Acambay

- Aculco

- Atlacomulco

- Chapa de Mota

- El Oro

- Jilotepec

- Jocotitlán

- Morelos

- Polotitlán,

- San José del Rincón

- Soyaniquilpan de Juárez

- Temascalcingo

- Timilpan

- Villa del Carbón.

Se trató de identificar cómo se vieron afectados, obtener información muy valiosa para la determinación de las mejores prácticas administrativas, con enfoque de proyectos y de Tecnologías de la 
Información y Comunicación (TIC), que muestren cómo debe ser la visión y misión para estas organizaciones frente a situaciones adversas como lo es una pandemia, para permitir que una microempresa subsista.

2. Estado del Arte

Las microempresas del sector comercio al por menor, también reconocidas por el término anglosajón retail, se encuentran ubicadas en la parte final de la cadena de suministro, son conformadas por unidades económicas dedicadas a la compra y venta de bienes para un consumidor final, destaca su clientela ya que es abundante, entre los diferentes tipos de negocios que se pueden encontrar se tienen las tiendas de ropa, alimentos, electrodomésticos, artículos tecnológicos (Páez, 2019; Manrique et al., 2019), aquellos que venden productos propios se les conoce como supermercados, agencias, depósitos, tiendas y su nombre tiende a ser el mismo que el del producto que comercializan, también existen quienes venden o promueven la compra-venta de bienes o servicios a través de una comisión, llamados también consignatarios, agentes importadores exportadores e intermediarios del comercio al por menor, son un vínculo entre mayoristas y consumidores. (Contreras, 2007; INEGI, 2020)

Datos recogidos de 99 países indican que el sector analizado representa el $70 \%$ del empleo total y son los que más empleo generan, $62 \%$ corresponden al sector informal con la respectiva brecha en cuanto a seguridad social, salarios, deficiencias, salud y relaciones laborales (OIT, 2019) Es importante destacar el dominio que las pequeñas y medianas empresas tienen sobre la economía en términos de concepción de empleo y riqueza. (Salazar et al., 2018)

En cuanto a la técnica seleccionada para evaluar la información obtenida, el Análisis Factorial Exploratorio (AFE) es una técnica para validación por excelencia que explora el conjunto de variables latentes, su confiabilidad y validez, que explican las respuestas a los ítems de un instrumento de medición e identifica su estructura de una manera profunda, es una de las técnicas más utilizadas para la validación y adaptación de instrumentos de medida psicológicos, utilizando desde los años 60 ha ido incrementándose de forma exponencial a un ritmo similar al avance de la informática (Lloret-Segura et al., 2014; Mendoza et al., 2009).

El estudio de los factores que benefician a las microempresas se ha investigado desde diferentes perspectivas, se han utilizado diversas técnicas para el análisis de la información obtenida para la toma de decisiones. En la literatura destacan trabajos sobre medición e impacto de las TIC en la gestión de las pequeñas y medianas empresas, es de destacar que su implementación impacta de forma positiva en el desarrollo organizacional y productivo generando valor agregado y ventajas competitivas (Cortes et al., 2016), un modelo para medir la madurez de las TIC de las pymes basado en 4 factores principales permite identificar factores sobre infraestructura, aplicación, recursos humanos y política de TIC. Se confirma que la madurez de las TIC de una empresa es una base sólida para la implementación exitosa de la gestión del conocimiento (Pham, 2010). Dicha situación se complementaría con 
la determinación de la Competencia Digital de los miembros de dichas entidades mediante la identificación de factores sobre el dominio de las Tecnologías de la Información y la Computación (Gutiérrez-Castillo et al, 2017; Baltazar et al., 2019) y el análisis de su Ciudadanía Digital (Baltazar et al., 2021) conceptos con un amplio rango de empleabilidad en la actualidad.

Es importante indicar que actualmente son diversas las nociones que se relacionan a la medición de la competitividad, no existen instrumentos para lograr dicha medición a nivel empresarial, lo cual es esencial para fomentar el incremento y el progreso, a nivel país como de los sectores económicos y empresas que lo conforman (Arriaga y González, 2012).En cuanto a innovación y el desarrollo tecnológico muchas veces no tienen los recursos para iniciar y gestionar proyectos, se encuentran restringidos por una serie de requerimientos como la estructura, los recursos financieros, el entorno y el sector (Estrada et al., 2019).

En cuanto a información fiscal, la recaudación de impuestos es la manera en que los gobiernos obtienen ingresos son de gran relevancia para las economías del mundo, gracias a ellos se invierte en aspectos fundamentales como la educación, salud, por citar algunos, su incumplimiento inhibe de forma importante la capacidad del gobierno para cubrir dichas necesidades, razón de la importancia por elaborar ítems que midan su cumplimiento en las microempresas (SAT, 2021).

Puesto que obtener utilidades o dar dinero a fundaciones no son las únicas responsabilidades que tienen las empresas, dichas premisas son actualmente obsoletas. Los paradigmas han ido transformándose de manera gradual hasta el punto en donde se conciben las actividades de las organizaciones en esferas tanto internas como externas, y cómo repercuten en dichos ámbitos. Es aquí donde toma una gran importancia el alcance real de la Responsabilidad Social Empresarial, debido a que, en términos internos, significa modificar los procesos de la empresa, para minimizar los impactos sociales que puede generar la actividad realizada. En términos externos, las organizaciones están interesadas en la necesidad de su implementación y los beneficios de una conducta socialmente responsable con un objetivo específico: el contribuir a un desarrollo sostenible y minimizar los impactos medioambientales (Baltazar, 2018).

3. Método

El paradigma para el desarrollo de la investigación es de tipo no experimental-transeccional y correlacional-explicativo, debido a que la recolección de la información a procesar se acopió en un único momento, para la obtención de las correlaciones de las variables propuestas, su manera de interacción y finalmente el desarrollo del AFE.

La muestra objeto de estudio, fue seleccionada de entre las microempresas del sector "comercio al por menor" de la región II Atlacomulco, utilizando la técnica de muestreo no probabilística, denominada causal o accidental (Hernández et al, 2014; Creswell, 2009), se configuró una muestra con un total de 400 unidades de negocio, se construyó un instrumento ad hoc para esta investigación denominado FFFRSI-COVID19, constituido por una dimensión socioeconómica y 
siete que analizaron aspectos financieros, fiscales, de responsabilidad social, informática, uso de las TIC, financiamiento y COVID-19 como se muestra en la Tabla 1. Este instrumento se encuentra validado por el cuerpo académico adscrito al Centro Universitario Atlacomulco de la Universidad Autónoma del Estado de México "Tendencias Financieras, Fiscales y de Responsabilidad Social en el siglo XXI”.

\begin{tabular}{|c|c|}
\hline VARIABLES & FUENTE \\
\hline SOCIODEMOGRÁFICAS & (Baltazar, 2016) \\
\hline FINANCIEROS & (Neftci, 2008) \\
\hline FISCALES & (SAT, 2021) \\
\hline \multirow{2}{*}{ RESPONSABILIDAD SOCIAL } & (ISO 26000:2010, 2010) \\
\cline { 2 - 2 } INFORMÁTICA & (Baltazar, 2018) \\
\hline COVID19 & (Gobierno de México, 2020) \\
\hline FINANCIAMIENTO & (Baltazar, 2016) \\
\hline USO DE LAS TIC EN EL NEGOCIO & (Baltazar et al., 2017) \\
\hline
\end{tabular}

Tabla 1. Variables Propuestas para el diseño del instrumento FFFRSI-COVID19 Fuente: Elaboración propia.

Se configuró una escala tipo Likert con 10 opciones de respuesta, lo que permite al encuestado situarse ante diferentes opciones (McMillan y Schumacher, 2010), pudiendo reflejar entre 1 y 10 el grado de usabilidad de la sentencia en su vida diaria, 1 significa que está completamente en desacuerdo y 10 completamente de acuerdo

Para la fase de recogida de datos se contactó vía WhatsApp con todos los alumnos de las Licenciaturas en Informática Administrativa, Administración y Contaduría del Centro Universitario UAEM Atlacomulco, quienes apoyaron a contactar a los dueños de negocios del sector "comercio al por menor" cercanos a su domicilio, evitando el trabajo de campo y una posible afección por el virus del COVID-19, a través de un formulario de Google Forms y el uso del programa WhatsApp así como sus redes sociales. En el formulario se indicó el objetivo principal del estudio y el aviso de privacidad, se optó por este tipo de formato debido a que facilita contactar a un gran número de posibles partícipes con celeridad y bajo costo (Díaz, 2010).

4. Resultados

En cuanto al análisis de datos a nivel descriptivo se identificó que el $57.75 \%$ de dichas microempresas se encuentra administrador por hombres y el $42.25 \%$ por mujeres; la edad promedio de la muestra es de 35.1 años; $38.5 \%$ cuenta con estudio de nivel preparatoria, $32 \%$ licenciatura o posgrado y $30 \%$ secundaria; $45 \%$ se ubican en el municipio de Atlacomulco, $10 \%$ en Temascalcingo y $8.5 \%$ son de Jocotitlán. 
En cuanto al giro destacan los denominados Venta de Abarrotes (10.5\%) como el principal, en segundo lugar los Servicios de Internet (8.5\%), en tercer lugar la Venta de Comida (7.5\%), en cuarto lugar las Papelerías (6.26\%), en quinto lugar las Carnicerías (6.25\%), en sexto lugar los Servicios de Profesionista Independientes (5.25\%), en séptimo lugar Venta de Ropa (4.75\%), en octavo lugar las Panaderías (4.5\%), noveno lugar la Venta de artículos de limpieza y plásticos (4\%) y en décimo lugar las Estéticas (3.75\%). En total suman el 61.25\% del total de la muestra.

Se reporta la siguiente longevidad:

- más de diez años (26.2\%),

- entre cinco y nueve años (20.5\%),

- dos años (14.8\%),

- menos de un año (10.5\%),

- un año $(8.6 \%)$ y

- tres años (5.2\%).

Sus ingresos mensuales son los siguientes:

- menos de cinco mil pesos (32.4\%),

- entre seis y diez mil pesos $(27.6 \%)$,

- entre once y veinte mil pesos (20\%),

- entre treinta y cuarenta mil pesos $(12.9 \%) \mathrm{y}$

- más de cincuenta mil pesos (7.1\%).

Los egresos del $90.5 \%$ de la muestra se encuentran entre menos de cinco mil pesos y máximo veinte mil pesos mensuales, reconociendo el $54.8 \%$ total que gasta menos de cinco mil pesos al mes.

Para iniciar el análisis de datos a través del AFE, en la tabla 2 se puede observar que la consistencia interna total del instrumento es satisfactoria (0.894), indicando así una correlación alta (Bisquerra, 2014; Mateo, 2006), el cual no mejoraría si se eliminase algún ítem del instrumento.

La fiabilidad obtenida en cada una de las dimensiones son también aceptables, siendo sus índices 0.827 (financieros), 0.890 (fiscales), 0.836 (responsabilidad social), .875 (informática), .811(COVID-19), .845 (financiamiento) y.830 (uso de las TIC en el negocio). Por tanto, se puede afirmar que los índices de consistencia interna obtenidos en las distintas puntaciones son aceptables, tanto para el conjunto de ítems como para cada bloque de ítems. 


\begin{tabular}{|c|c|c|c|c|}
\hline íte- & \begin{tabular}{|} 
Media de escala \\
si el elemeeto se \\
ba soprimido
\end{tabular} & $\begin{array}{l}\text { Varianza de escala } \\
\text { si el elemento se ba } \\
\text { suprieido }\end{array}$ & $\begin{array}{l}\text { Correlación total de } \\
\text { elementos corregida }\end{array}$ & $\begin{array}{c}\text { Alfa de Cronbach si } \\
\text { el elemento se bo } \\
\text { suprimido }\end{array}$ \\
\hline 1 & 197.98 & 2668.98 & 0.550 & 0.869 \\
\hline 2 & 195.81 & 2706.40 & 0.490 & 0.890 \\
\hline 3 & 194.72 & 2781.49 & 0.343 & 0.892 \\
\hline 4 & 195.96 & 2713.79 & 0.481 & 0.890 \\
\hline 5 & 195.73 & 2719.32 & 0.514 & 0.890 \\
\hline 6 & 197.42 & 2633.36 & 0.561 & 0.888 \\
\hline 7 & 197.40 & 2624.37 & 0.572 & 0.888 \\
\hline 8 & 196.66 & 2675.70 & 0.521 & 0.889 \\
\hline 9 & 196.27 & 2679.05 & 0.547 & 0.869 \\
\hline 10 & 198.10 & 2636.09 & 0.587 & 0.888 \\
\hline 11 & 194.65 & 2754.05 & 0.373 & 0.892 \\
\hline 12 & 197.62 & 2632.49 & 0.592 & 0.888 \\
\hline 13 & 196.95 & 2661.98 & 0.575 & 0.888 \\
\hline 14 & 197.23 & 2638.63 & 0.594 & 0.888 \\
\hline 15 & 195.78 & 2674.44 & 0.571 & 0.888 \\
\hline 16 & 194.29 & 2759.84 & 0.412 & 0.891 \\
\hline 17 & 194.35 & 2740.78 & 0.484 & 0.890 \\
\hline 18 & 194.43 & 2741.23 & 0.458 & 0.891 \\
\hline 19 & 196.79 & 2659.23 & 0.604 & 0.868 \\
\hline 20 & 195.05 & 2721.55 & 0.466 & 0.890 \\
\hline 21 & 195.76 & 2809.45 & 0.159 & 0.895 \\
\hline 22 & 195.98 & 2822.76 & 0.116 & 0.896 \\
\hline 23 & 198.62 & 2783.67 & 0.213 & 0.894 \\
\hline 24 & 194.68 & 2826.48 & 0.120 & 0.895 \\
\hline 25 & 199.79 & 2767.51 & 0.262 & 0.894 \\
\hline 26 & 199.69 & 2814.23 & 0.154 & 0.895 \\
\hline 27 & 200.36 & 2780.02 & 0.288 & 0.893 \\
\hline 28 & 199.06 & 2729.90 & 0.361 & 0.892 \\
\hline 29 & 200.68 & 2800.60 & 0.239 & 0.893 \\
\hline 30 & 200.91 & 2832.80 & 0.145 & 0.894 \\
\hline 31 & 199.40 & 2784.34 & 0.240 & 0.894 \\
\hline 32 & 198.09 & 2685.72 & 0.426 & 0.891 \\
\hline 33 & 199.31 & 2698.45 & 0.428 & 0.891 \\
\hline 34 & 196.44 & 2714.40 & 0.353 & 0.892 \\
\hline 35 & 198.63 & 2680.19 & 0.446 & 0.890 \\
\hline 36 & 198.23 & 2666.19 & 0.464 & 0.890 \\
\hline
\end{tabular}

Tabla 2: Estadísticos Total Elemento

Fuente: Elaboración propia con datos de SPSS 25 versión de prueba.

El índice de adecuación muestral de Kaiser-Meyer-Olkin (KMO) obtuvo un valor de .829 para los ítems del instrumento, indicando una correcta adecuación de los datos para efectuar el Análisis Factorial Exploratorio. La prueba esfericidad de Bartlett resultó significativa $(\chi 2=$ 4395.801, g.l.= 630 y p<.0001), indicando así el buen ajuste del modelo. La solución factorial está formada por siete factores que se extrajeron después de la rotación Varimax, cuyo proceso convergió en la séptima iteración, lo cual explica el 63.202\% de la varianza total (consultar Tabla $3)$. 


\begin{tabular}{|c|c|c|c|c|c|c|c|c|c|}
\hline \multirow{2}{*}{ Componente } & \multicolumn{3}{|c|}{ Autovalores iniciales } & \multicolumn{3}{|c|}{$\begin{array}{c}\text { Sumas de cargas al } \\
\text { cuadrado de la extracción }\end{array}$} & \multicolumn{3}{|c|}{$\begin{array}{c}\text { Sumas de cargas al cuadrado } \\
\text { de la rotación }\end{array}$} \\
\hline & Total & $\begin{array}{c}\text { \% de } \\
\text { yarianza }\end{array}$ & $\begin{array}{c}\% \\
\text { acumulado }\end{array}$ & Total & $\begin{array}{c}\text { \% de } \\
\text { varianza }\end{array}$ & acumulad & Total & $\begin{array}{c}\text { \% de } \\
\text { varianza }\end{array}$ & acumulad \\
\hline 1 & 8.7 & 24.153 & 24.153 & 8.695 & 24.153 & 24.153 & 3.907 & 10.852 & 10.852 \\
\hline 2 & 3.78 & 10.497 & 34.65 & 3.779 & 10.497 & 34.65 & 3.789 & 10.525 & 21.377 \\
\hline 3 & 2.8 & 7.765 & 42.415 & 2.795 & 7.765 & 42.415 & 3.369 & 9.359 & 30.735 \\
\hline 4 & 2.63 & 7.315 & 49.73 & 2.633 & 7.315 & 49.73 & 3.213 & 8.925 & 39.661 \\
\hline 5 & 1.88 & 5.21 & 54.94 & 1.875 & 5.21 & 54.94 & 3.153 & 8.758 & 48.419 \\
\hline 6 & 1.66 & 4.606 & 59.546 & 1.658 & 4.606 & 59.546 & 2.993 & 8.314 & 56.733 \\
\hline 7 & 1.32 & 3.656 & 63.202 & 1.316 & 3.656 & 63.202 & 2.21 & 6.14 & 62.873 \\
\hline 8 & 1.05 & 2.929 & 66.131 & & & & & & \\
\hline 9 & 0.99 & 2.74 & 68.871 & & & & & & \\
\hline 10 & 0.94 & 2.622 & 71.493 & & & & & & \\
\hline 11 & 0.9 & 2.489 & 73.982 & & & & & & \\
\hline 12 & 0.87 & 2.429 & 76.411 & & & & & & \\
\hline 13 & 0.76 & 2.119 & 78.53 & & & & & & \\
\hline 14 & 0.68 & 1.896 & 80.426 & & & & & & \\
\hline 15 & 0.64 & 1.778 & 82.204 & & & & & & \\
\hline 16 & 0.56 & 1.564 & 83.768 & & & & & & \\
\hline 17 & 0.53 & 1.464 & 85.232 & & & & & & \\
\hline 18 & 0.52 & 1.432 & 86.665 & & & & & & \\
\hline 19 & 0.49 & 1.349 & 88.014 & & & & & & \\
\hline 20 & 0.46 & 1.275 & 89.289 & & & & & & \\
\hline 21 & 0.43 & 1.2 & 90.489 & & & & & & \\
\hline 22 & 0.39 & 1.073 & 91.562 & & & & & & \\
\hline 23 & 0.37 & 1.025 & 92.587 & & & & & & \\
\hline 24 & 0.34 & 0.952 & 93.539 & & & & & & \\
\hline 25 & 0.33 & 0.912 & 94.451 & & & & & & \\
\hline 26 & 0.31 & 0.847 & 95.298 & & & & & & \\
\hline 27 & 0.25 & 0.696 & 95.994 & & & & & & \\
\hline 28 & 0.24 & 0.669 & 96.663 & & & & & & \\
\hline 29 & 0.22 & 0.598 & 97.262 & & & & & & \\
\hline 30 & 0.21 & 0.569 & 97.831 & & & & & & \\
\hline 31 & 0.18 & 0.508 & 98.339 & & & & & & \\
\hline 32 & 0.17 & 0.458 & 98.797 & & & & & & \\
\hline 33 & 0.14 & 0.379 & 99.176 & & & & & & \\
\hline 34 & 0.12 & 0.323 & 99.499 & & & & & & \\
\hline 35 & 0.1 & 0.288 & 99.787 & & & & & & \\
\hline 36 & 0.08 & 0.213 & 100 & & & & & & \\
\hline
\end{tabular}

Tabla 3. Componentes y varianza total explicada.

Fuente: Elaboración propia con datos de SPSS 25 versión de prueba.

El número de componentes que pueden adoptarse queda también indicado en el gráfico de sedimentación (véase Figura 1), donde se ha aplicado la prueba Scree de Cattell.

En la Tabla 4 se idéntica que el primer factor explica el $24.15 \%$ y está conformado por los cinco ítems de la dimensión Financieros. El segundo factor explica el $36.65 \%$ e incluye los cinco ítems de la dimensión Fiscales. El tercer factor explica el $42.42 \%$ y está formado por los cinco ítems de Responsabilidad Social. El cuarto factor está constituido por los cinco ítems de Informática y explica el $49.73 \%$. El quinto factor explica el 54.94\% y está formado por los cinco ítems del factor COVID19. El sexto factor explica el $59.55 \%$ y está constituido por los cinco ítems de Financiamiento. Finalmente el séptimo factor explica el $63.20 \%$ y está conformado por los cinco ítems de Uso de las TIC en el Negocio. 


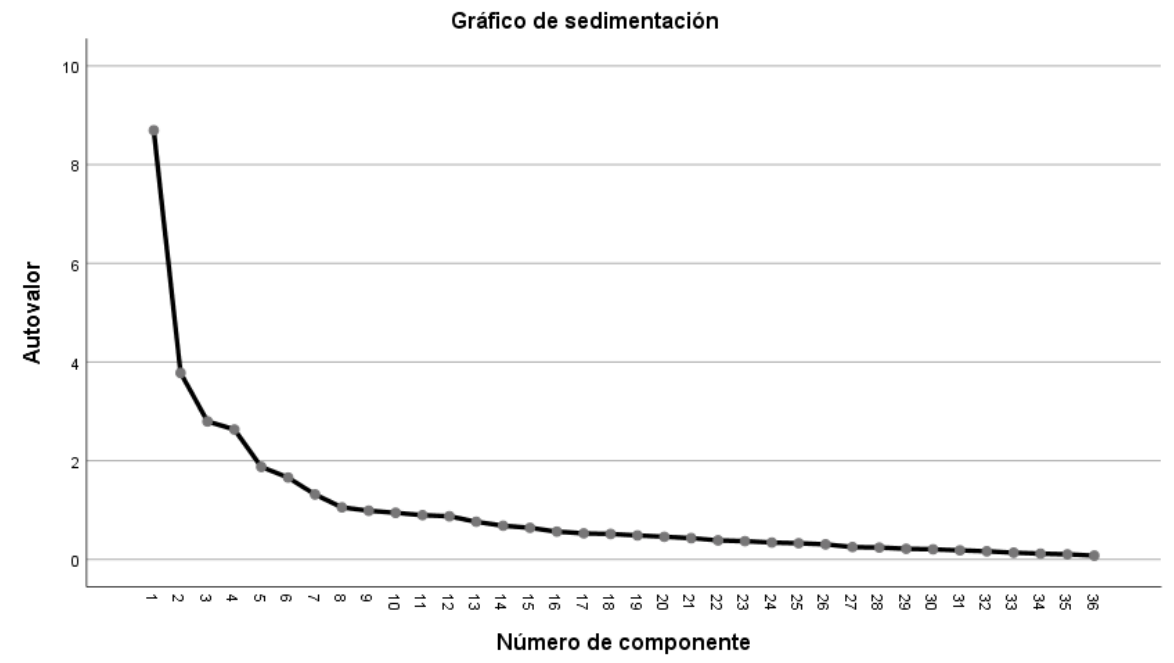

Figura 1. Gráfico de Sedimentación

Fuente: Elaboración propia con datos de SPSS 25 versión de prueba.

A continuación se muestra la matriz de correlaciones en la tabla 5 donde se logran apreciar las relaciones significativas entre las variables propuestas, éstas se denotan con doble asterisco $\left({ }^{* *}\right)$, destacan de manera importante la del factor COVID-19 cuyo análisis permite afirmar que las unidades de negocio entrevistadas no se vieron afectadas por la actual pandemia, es decir, no cerraron operaciones, con la única variable con la cual muestra correlación fue con FINANCIAMIENTO, lo cual se puede interpretar que las microempresas del sector comercio al por menor de la muestra seleccionada procuró no endeudarse con bancos, casas de empeño y microfinancieras, así mismo no tuvieron apoyo por parte del gobierno, el único financiamiento que aceptaron fue el de sus familias. 


\begin{tabular}{|c|c|c|c|c|c|c|c|}
\hline íte- & 1 & 2 & 3 & 4 & 5 & 6 & 7 \\
\hline 1 & 0.89 & & & & & & \\
\hline 2 & 0.85 & & & & & & \\
\hline 3 & 0.81 & & & & & & \\
\hline 4 & 0.79 & & & & & & \\
\hline 5 & 0.49 & & & & & & \\
\hline 6 & & 0.49 & & & & & \\
\hline 7 & & 0.83 & & & & & \\
\hline 8 & & 0.82 & & & & & \\
\hline 9 & & 0.76 & & & & & \\
\hline 10 & & 0.75 & & & & & \\
\hline 11 & & & 0.66 & & & & \\
\hline 12 & & & 0.89 & & & & \\
\hline 13 & & & 0.86 & & & & \\
\hline 14 & & & 0.79 & & & & \\
\hline 15 & & & 0.73 & & & & \\
\hline 16 & & & & 0.41 & & & \\
\hline 17 & & & & 0.8 & & & \\
\hline 18 & & & & 0.76 & & & \\
\hline 19 & & & & 0.76 & & & \\
\hline 20 & & & & 0.6 & & & \\
\hline 21 & & & & & 0.56 & & \\
\hline 22 & & & & & 0.54 & & \\
\hline 23 & & & & & 0.41 & & \\
\hline 24 & & & & & 0.76 & & \\
\hline 25 & & & & & 0.74 & & \\
\hline 26 & & & & & & 0.710 & \\
\hline 27 & & & & & & 0.68 & \\
\hline 28 & & & & & & 0.61 & \\
\hline 29 & & & & & & 0.76 & \\
\hline 30 & & & & & & 0.76 & \\
\hline 31 & & & & & & 0.71 & \\
\hline 32 & & & & & & & 0.67 \\
\hline 33 & & & & & & & 0.91 \\
\hline 34 & & & & & & & 0.9 \\
\hline 35 & & & & & & & 0.55 \\
\hline 36 & & & & & & & 0.86 \\
\hline
\end{tabular}

Tabla 4. Matriz de Componentes Rotados Fuente: Elaboración propia con datos de SPSS 25 versión de prueba.

\begin{tabular}{|c|c|c|c|c|c|c|c|c|}
\hline VARIABLES & CORRELACIONES & FINANCIEROS & FISCALES & $\begin{array}{l}\text { RESPONSABILIDAD } \\
\text { SOCIAL }\end{array}$ & INFORMATICA & covidis & FINANCIAMIENTO & USO DE LAS TIC \\
\hline \multirow[t]{3}{*}{ FINANCIEROS } & Correlación de Pearson & 1 & $.435^{* *}$ & $.592^{* *}$ & .483" & 0.049 & 0.047 & $.266^{*}$ \\
\hline & Sig. (bilateral) & & 0 & 0 & 0 & 0.478 & 0.496 & 0 \\
\hline & N & 210 & 210 & 210 & 210 & 210 & 210 & 210 \\
\hline \multirow[t]{3}{*}{ FISCALES } & Correlación de Pearson & $.435^{* *}$ & 1 & $.564^{\prime \prime}$ & $.332^{* *}$ & $.164^{*}$ & $.153^{*}$ & $.304^{* *}$ \\
\hline & Sig.(bilateral) & 0 & & 0 & 0 & 0.018 & 0.026 & 0 \\
\hline & $\mathrm{N}$ & 210 & 210 & 210 & 210 & 210 & 210 & 210 \\
\hline RESPONSABILIDAD & Correlación de Pearson & $.592^{* *}$ & $.564^{\prime \prime}$ & 1 & $.492^{* *}$ & 0.068 & 0.096 & $.329^{* *}$ \\
\hline \multirow[t]{2}{*}{ SOCIAL } & Sig.(bilateral) & 0 & 0 & & 0 & 0.326 & 0.166 & 0 \\
\hline & $\mathrm{N}$ & 210 & 210 & 210 & 210 & 210 & 210 & 210 \\
\hline \multirow[t]{3}{*}{ INFORMATICA } & Correlación de Pearson & $.483^{* *}$ & $.332^{* *}$ & $.492^{* 2}$ & 1 & 0.093 & 0.062 & $.308^{* *}$ \\
\hline & Sig. (bilateral) & 0 & 0 & 0 & & 0.179 & 0.368 & 0 \\
\hline & N & 210 & 210 & 210 & 210 & 210 & 210 & 210 \\
\hline \multirow[t]{3}{*}{ CoviD19 } & Correlación de Pearson & 0.049 & $.164^{*}$ & 0.068 & 0.093 & 1 & $.331^{* *}$ & 0.07 \\
\hline & Sig.(bilateral) & 0.478 & 0.018 & 0.326 & 0.179 & & 0 & 0.312 \\
\hline & N & 210 & 210 & 210 & 210 & 210 & 210 & 210 \\
\hline \multirow[t]{3}{*}{ FINANCIAMIENTO } & Correlación de Pearson & 0.047 & $.153^{*}$ & 0.096 & 0.062 & $.331^{* *}$ & 1 & $.218^{* *}$ \\
\hline & Sig.(bilateralal) & 0.496 & 0.026 & 0.166 & 0.368 & 0 & & 0.001 \\
\hline & $\mathrm{N}$ & 210 & 210 & 210 & 210 & 210 & 210 & 210 \\
\hline \multirow[t]{3}{*}{ USO DE LAS TIC } & Correlación de Pearson & $.266^{*+}$ & $.304^{* *}$ & $.329^{* *}$ & $.308^{* *}$ & 0.07 & $.218^{*+}$ & 1 \\
\hline & Sig.(bilateral) & 0 & 0 & 0 & 0 & 0.312 & 0.001 & \\
\hline & $\mathrm{N}$ & 210 & 210 & 210 & 210 & 210 & 210 & 210 \\
\hline
\end{tabular}

Tabla 5. Matriz de Correlaciones

Fuente: Elaboración propia con datos de SPSS 25 versión de prueba.

La muestra seleccionada reportó conocimiento de factores Informáticos (78.42\%), Financieros (67.82\%), de Responsabilidad Social (63.76\%), COVID19 (58.67\%), Fiscales (56.53\%), de Uso de las TIC 
(46.89\%) y poca necesidad de Financiamiento (22.36\%). Destaca el saber que sus operaciones se vieron afectadas de forma parcial por la pandemia (75\%), en este caso surge la hipótesis que el Uso de las TIC en el Negocio o el factor Informática (al ser el mejor posicionado) haya influido de manera directa pero de manera lamentable no se vio reflejado este supuesto en la tabla de correlación puesto que casi 5 de cada 10 microempresas del sector comercio al por menor las utilizaron, definitivamente esto es un área de oportunidad del instrumento. Para el $70.69 \%$ sus ventas disminuyeron; el $23.56 \%$ tuvo que cerrar su negocio; $82.56 \%$ informan que algunos familiares y conocidos tuvieron contagio de COVID-19; y el 25.19\% tuvo contagio, se confirma que 3 de cada 10 unidades de negocio cerraron durante la pandemia, el $70 \%$ operó con normalidad.

En cuanto a la interpretación del AFE se tiene lo siguiente; el primer factor está conformado por los ítems de Financieros, el 52\% elaboran reportes financieros periódicamente, $65.6 \%$ saben claramente cuánto capital propio y financiamiento tiene su empresa, $83.4 \%$ identifican que su inventario se apega a las necesidades de sus clientes, $65.65 \%$ elaboran un presupuesto de ingresos y gastos y lo aplican en el negocio, finalmente el $72.45 \%$ tienen identificado el porcentaje real de rendimiento, se identificó una correlación alta y estadísticamente significativa con todas la variables excepto COVID-19 y financiamiento.

El segundo factor se encuentra integrado por los ítems de Fiscales. El 55.9\% reporta que la organización donde trabajan se encuentra inscrita al Registro Federal de Contribuyentes; 58.25\% hacen sus pagos provisionales en tiempo y forma ante el SAT, con base a su régimen fiscal; $59.65 \%$ creen que el pago de las obligaciones fiscales contribuye al gasto público para solventar las problemáticas del país; $64.65 \%$ consideran al SAT una organización indispensable para la recaudación de los impuestos de las empresas y el 50.25\% usa la plataforma del SAT, que se encuentra en Internet, para cumplir con sus obligaciones fiscales. Se identificó una correlación alta y estadísticamente significativa con todas las variables del instrumento excepto con COVID-19 y financiamiento.

El tercer factor integrado por los ítems de Responsabilidad Social, afirman con un $78.75 \%$ que, en la organización donde laboran, existe una cultura de respeto a los derechos humanos; $59.6 \%$ cuentan con un contrato de trabajo en donde se especifica la relación laboral, los derechos y obligaciones, tanto de empleadores como de empleados; 63.15\% cuenta con métodos para medir, registrar e informar acerca de sus fuentes de contaminación significativas y reducir la contaminación, el consumo de agua, la generación de residuos y el consumo de energía; $59.75 \%$ indican que también cuentan con un sistema que identifica los riesgos de corrupción, implementa y mantiene políticas y prácticas que combatan la corrupción, y la extorsión; finalmente, el 73.2\% reportan que la empresa comunica información completa, clara o cierta, que pueda tener como resultado que los consumidores adquieran productos y servicios que satisfagan sus necesidades, sin ser incluso peligrosos para el consumidor o el medio ambiente. Se reportan una correlación alta 
y estadísticamente significativa con todas las variables del instrumento, excepto con COVID-19 y financiamiento.

El cuarto factor se encuentra conformado por los ítems de Informática. El $85.05 \%$ considera que en el futuro la mayoría de las actividades humanas estarán ligadas a una conexión de internet; $84.2 \%$ es consciente de la importancia de la conectividad de los dispositivos con base en el internet de las cosas; $86.15 \%$ considera que el uso de programas y sistemas computacionales son necesarios para las actividades en el día a día; $61.05 \%$ indican que sus habilidades en cuanto al uso del software ofimático son excelentes y me mantienen en constante actualización: finalmente, el 79.65\% consideran que el dominio de las redes sociales es imprescindible en la actualidad para interactuar con nuestros semejantes (Facebook, Twitter). Se identifica una correlación alta y estadísticamente significativa con todas las variables del instrumento, excepto con COVID-19 y Financiamiento.

El quinto factor se encuentra constituido por los ítems de COVID-19. La muestra analizada reporta, en un $75.5 \%$ que la pandemia afectó a su negocio; que el $72.3 \%$ sufrió una disminución de sus ventas; que el $43.95 \%$ tuvo que cerrar su negocio. Además, $80.1 \%$ reconoce que algunos familiares y conocidos tuvieron contagio de coronavirus y el $28.3 \%$ tuvo síntomas o contagio. Se identificó una correlación alta y estadísticamente significativa sólo con la variable Financiamiento.

El sexto factor se encuentra conformado por los ítems de Financiamiento. Se tiene que sólo el $33.65 \%$ ha tenido la necesidad de recurrir a préstamos en microfinancieras para no cerrar su negocio; que el $26.4 \%$ solicitó un crédito bancario para no cerrar; que para el $39.3 \%$ sus proveedores le ofrecieron crédito; que $26.15 \%$ recurrió a casas de empeño para obtener financiamiento y no cerrar el negocio; que el $17.10 \%$ recibió apoyo financiero del gobierno; y que el $34.85 \%$ tuvo apoyo de su familia para evitar el cierre del establecimiento. Se identifica una correlación alta y estadísticamente significativa únicamente con COVID-19 y Uso de las TIC.

Finalmente el séptimo factor se encuentra integrado por los ítems de Uso de las TIC. Se reporta que el 49.5\% utilizó la red social de Facebook para promocionar y vender sus productos; $32.8 \%$ utilizó la red social Instagram para promocionar y vender sus productos; $59.35 \%$ con sus clientes más cercanos utilizó algún programa como WhatsApp o Telegram para vender sus productos; en $43.85 \%$ de los casos reconocieron que su negocio tiene página web, página de Facebook o Instagram; y el $44.7 \%$ indican que su negocio se puede localizar en Google Maps. Se identifica una correlación alta y estadísticamente significativa con todas las variables del instrumento, excepto con COVID-19.

5. Conclusiones y recomendaciones

Las microempresas del sector comercio al por menor de la región II de Atlacomulco, como seguramente en el resto del país y del mundo, indudablemente se han visto afectadas por las restricciones sanitarias que se han impuesto por los ayuntamientos para continuar sus operaciones. En definitiva, el instrumento FFFRSI-COVID-19 permitió analizar 
datos socioeconómicos, financieros, fiscales, de responsabilidad social e informática y cómo se vieron afectados por la actual pandemia. Indudablemente la constante medición de éstas variables permitirá la toma de decisiones, por lo que otra de las metas futuras será mejorar el instrumento y continuar con su aplicabilidad, no sólo a nivel región, sino a nivel estatal y posteriormente a nivel nacional. Cuestiones como el financiamiento y la capacidad para contactar con microempresarios de otras regiones se podría subsanar con apoyo de universidades hermanas y otros organismos. Incluso las redes internacionales que se tienen a nivel UAEMéx podrían ser una alternativa para lograr llegar a más microempresas.

Se afirma que una gran parte de alumnos egresados de estudios superiores se encuentra gestionando emprendimientos. Una posible razón de esto sea la falta de empleos formales. Así mismo se destaca la capacidad en la toma de decisiones de los factores ya mencionados, debido al porcentaje que se tienen de microempresas administradas por personas con estudios de nivel medio superior, licenciatura y posgrado, quienes también reportan un porcentaje alto para el manejo de TIC. Este tipo de individuos consideran que en el futuro la mayoría de las actividades humanas estarán ligadas a una conexión de internet. Están conscientes de la importancia de la conectividad de los dispositivos con base en el internet de las cosas. Consideran que el uso de programas y sistemas computacionales son necesarios para las actividades en el día a día. Cuentan con habilidades en cuanto al uso del software ofimático y se mantienen en constante actualización. De igual forma, consideran que el dominio de las redes sociales es imprescindible en la actualidad para interactuar con nuestros semejantes, sobre todo en épocas de pandemia; con lo cual lograron continuar la promoción y venta de sus productos, destacando el uso de plataformas como Facebook y el uso de software en dispositivos móviles como Whatsapp y Telegram, así como la importancia de que las personas ubiquen su negocio en Google Maps.

También es una tarea pendiente por parte de la actual administración gubernamental, puesto que se detectó un muy bajo nivel de apoyo para éste sector, literalmente se vieron en la necesidad de pedir apoyo económico en el núcleo familiar como primera opción y en el menor de los casos solicitar préstamos en bancos, microfinancieras y casas de empeño. La pandemia de COVID-19 afectó a cada negocio del sector evaluado, sus ventas disminuyeron y cuatro de cada diez microempresas cerraron, así mismo ocho de cada diez tuvieron familiares y conocidos que tuvieron contagio de coronavirus mientras que tres de cada diez sufrieron síntomas o contagio.

Para finalizar, la pandemia del COVID-19 ha venido a afectar las actividades humanas a todos niveles, las unidades de negocio se han visto afectadas debido a las restricciones sanitarias que se imponen por las autoridades buscando minimizar el impacto del virus entre la población y el incremento de nivel de mortandad, efectivamente a través del instrumento propuesto se logró determinar el impacto de la pandemia de COVID-19 en las microempresas del sector comercio al por menor de los 
municipios de la Región II Atlacomulco, Estado de México, considerando al Análisis Factorial Exploratorio, como técnica de análisis de datos, consiguiendo identificar qué factores se encuentran correlacionados.

Agradecimientos

Al cuerpo académico "Tendencias Financieras, Fiscales y de Responsabilidad Social en el Siglo XXI" del Centro Universitario Atlacomulco adscrito a la Universidad Autónoma del Estado de México y a los alumnos de las Licenciaturas de Informática Administrativa, Contaduría y Administración de la misma institución por el apoyo brindado para el desarrollo de la presente investigación.

\section{Referencias}

Arriaga, K., y González, T. (2012). Diseño y validación de instrumento para medir el nivel de competitividad en Pequeñas Empresas del sector TIC de la Región Metropolitana. Revista Gestión de las Personas y Tecnología. https://bit.ly/3bcGITb

Baltazar, C. (2018). Diseño y validación de un instrumento basado en la Norma ISO-26000:2010 para la identificación de prácticas sobre responsabilidad social empresarial. Editorial Río Subterráneo.

Baltazar, C., Martínez, Y., Sámano, A., Corte, F., Evangelista, E., y Mercado, V. (2019). Análisis de la competencia digital en los estudiantes de la licenciatura en informática administrativa del CU. UAEM. Atlacomulco. Revista In Crescendo. Universidad Católica Los Ángeles de Chimbote. https://doi.org/10.21895/incres.2019.v10n1.11

Baltazar, C., Sámano, A., Martínez, Y., y Garduño, A. (2021). Análisis de la Ciudadanía Digital en alumnos de una Institución Universitaria en épocas de Pandemia. In Crescendo. Universidad Católica Los Ángeles de Chimbote. Chimbote. https://bit.ly/3B5a9B1. https:// doi.org/10.21895/incres.2020.v11n4.02

Bisquerra, R. (2014). Metodología de la investigación educativa. Madrid: La Muralla.

Contreras, R. (2007). Necesidades del Comercio al por Menor en Celaya. Pequeños y micro negocios. Biblioteca virtual de Derecho, Economía y Ciencias Sociales. https://bit.ly/30TmWKw

Copladem. (2017). Comité de Planeación para el Desarrollo del Estado de México. Regiones y Municipios. Secretaría de Finanzas. https:// bit.ly/3p37oxG

Cortes, J., Páez, J., y Lozano, J. (2016). Application of ICT in systems management of the port SME sector. Redes de Ingeniería. Universidad Distrital Francisco José de Caldas. http://dx.doi.org/10.14483/ udistrital.jour.redes.2016.1.a5

Creswell, J. (2009). Research Design. Qualitative, Quantitative and Mixed Methods Aproaches. SAGE Publications, Inc.

Díaz, V. (2010). Eficacia de las encuestas por internet: Un estudio preliminar. Revista española de Sociología. 13, 49-79. https://bit.ly/3nll04Q

Durán, P. (2017, 6 de julio). Microempresas, PyMEs y Objetivos de Desarrollo Sostenible. Nacionales Unidas México. https://bit.ly/3BJF3zZ 
Estrada, S., Cano, K., y Aguirre, J. (2019). ¿Cómo se gestiona la tecnología en las pymes? Diferencias y similitudes entre micro, pequeñas y medianas empresas. Contaduría y Administración. 64(1), 72. https:// bit.ly/3vCCuh0

Filión, L. (2011). Administración de PYMES. 1ª ed. Pearson Educación. México, 2011.

Gutiérrez-Castillo, J.J., Cabero-Almenara, J., y Estrada-Vidal, L.I. (2017). Diseño y validación de un instrumento de evaluación de la competencia digital del estudiante universitario. Revista Espacios. Vol. 38. https:// bit.ly/3b4QAy5

Hernández, S. R., Fernández, C. C., y Baptista, L. P. (2014). Metodología de la Investigación. Sexta Edición, Editorial Mc Graw Hill / Interamericana Editores S.A. de C.V. México. D.F.

INEGI. (2020). Encuesta anual de comercio 2020. Síntesis Metodológica. https://bit.ly/3vKqaeP

Lloret-Segura, Ferreres, A., Hernández, A., y Tomás, I. (2014). El análisis factorial exploratorio de los ítems: Una guía práctica, revisada y actualizada. Anales de Psicología. 30(3), 1151-1169. https:// bit.ly/3pqZUF5

Macmillan, J., y Schumacher, S. (2010). Investigación educativa: Una introducción conceptual. Madrid: Pearson-Addison Wesley.

Manrique, N., Teves, J., Taco, A., y Flores, J. (2019). Gestión de cadena de suministro: una mirada desde la perspectiva teórica. Revista Venezolana de Gerencia, vol. 24, núm. 88. Universidad del Zulia. https://bit.ly/3vD4aSI

Mateo, J. (2006). La investigación expost-facto. En Rafael Bisquerra (cood.), Metodología de la investigación educativa (pp. 195-230). Madrid: La Muralla.

Mendoza, J., y Garza, J. B. (2009). La medición en el proceso de investigación científica: Evaluación de validez de contenido y confiabilidad. (Measurement in the scientific research process: Content validity and reliabixlity evaluation). Innovaciones de Negocios 6(1): 17-32. https:// bit.ly/3B0ZwPG

OIT. (2019). La mayor parte del empleo mundial procede de las pequeñas empresas y los trabajadores independientes. https://bit.ly/2XBjSBo

Páez, G. (2019, 11 de noviembre). Comercio al por menor. Economipedia. https://bit.ly/3ptTdCi

Pham, Q. T. (2010). Measuring The ICT Maturity Of SMEs. Journal of Knowledge Management Practice. Vol. 11, No. 1. https://bit.ly/3C7KyJ7

Salazar, B., Mendoza, J., y Martínez, M. (2018). Factores competitivos de éxito: un estudio de las pymes en el Estado de Hidalgo, México. https:// doi.org/10.19044/esj.2018.v14n34p65

SAT. (2021). Por qué pagar impuestos. https://bit.ly/2ZhOOak 